\title{
BMJ Open Factors associated with high compliance behaviour against COVID-19 in the early phase of pandemic: a cross- sectional study in 12 Asian countries
}

To cite: Chua CE, Kew GS, Demutska A, et al. Factors associated with high compliance behaviour against COVID-19 in the early phase of pandemic: a cross-sectional study in 12 Asian countries. BMJ Open 2021;11:e046310. doi:10.1136/ bmjopen-2020-046310

- Prepublication history and supplemental material for this paper is available online. To view these files, please visit the journal online (http://dx.doi. org/10.1136/bmjopen-2020046310).

CEC and GSK are joint first authors.

JP and KTHS are joint senior authors.

Received 27 October 2020 Accepted 26 July 2021

Check for updates

(C) Author(s) (or their employer(s)) 2021. Re-use permitted under CC BY-NC. No commercial re-use. See rights and permissions. Published by BMJ.

For numbered affiliations see end of article.

Correspondence to Dr Junxiong Pang; ephpjv@nus.edu.sg

\section{ABSTRACT}

Introduction Regardless of having effective vaccines against COVID-19, containment measures such as enhanced physical distancing and good practice of personal hygiene remain the mainstay of controlling the COVID-19 pandemic. Countries across Asia have imposed these containment measures to varying extents. However, residents in different countries would have a differing degree of compliance to these containment measures potentially due to differences in the level of awareness and motivation in the early phase of pandemic.

Objectives In our study, we aimed to describe and correlate the level of knowledge and attitude with the level of compliance with personal hygiene and physical distancing practices among Asian countries in the early phase of pandemic.

Methods A multinational cross-sectional study was carried out using electronic surveys between May and June 2020 across 14 geographical areas. Subjects aged 21 years and above were invited to participate through social media, word of mouth and electronic mail.

Results Among the 2574 responses obtained, 762 $(29.6 \%)$ participants were from East Asia and 1812 $(70.4 \%)$ were from Southeast Asia (SEA). A greater proportion of participants from SEA will practise physical distancing as long as it takes ( $72.8 \%$ vs $60.6 \%)$. Having safe distancing practices such as standing more than 1 or $2 \mathrm{~m}$ apart (AdjOR $5.0995 \% \mathrm{Cl}$ (1.08 to 24.01)) or more than 3 or $4 \mathrm{~m}$ apart (AdjOR $7.0595 \% \mathrm{Cl}(1.32$ to 37.67)), wearing a mask when they had influenza-like symptoms before the COVID-19 pandemic, preferring online news channels such as online news websites/ applications (AdjOR 1.73 95\% Cl (1.21 to 2.49)) and social media (AdjOR $1.6895 \% \mathrm{Cl}$ (1.13 to 2.50) as sources of obtaining information about COVID-19 and high psychological well-being (AdjOR 1.39 95\% Cl (1.04 to 1.87)) were independent factors associated with high compliance.

Conclusions We found factors associated with high compliance behaviour against COVID-19 in the early phase
Strengths and limitations of this study

This study addresses the gap in literature by using a multinational cross-sectional survey to provide in-depth exploration of general public's knowledge, attitude and practice (KAP) of personal hygiene and physical distancing in East Asia and Southeast Asia.

- Quantitative analysis reveals key factors associated with high compliance to provide policy makers useful information on the KAP of COVID-19 containment measures to guide public health policies.

- KAP instrument used in this study could have a more thorough assessment of its instrument validity and reliability to be more robust.

- Although this cross-sectional study design can only demonstrate associations between patterns and social-demographic variables, it can guide future cohort study to demonstrate causations.

of pandemic and it will be useful to consider them in risk assessment, communication and pandemic preparedness.

\section{INTRODUCTION}

The novel COVID-19 was first reported in December 2019 and has currently more than 166 million reported cases globally with over 3.4 million deaths as of 24 May 2021. ${ }^{1}$ While mRNA-1273 vaccine showed $94.1 \%$ efficacy at preventing COVID-19 illness $^{2}$ and vaccination reduced the overall attack rate to $4.6 \%$ from $9.0 \%$ without vaccination over 300 days, ${ }^{3}$ the virus that causes COVID-19, SARS-CoV-2, may well mutate; the eventual vaccine may provide only partial protection; and, notably, vaccine hesitancy may preclude large-scale uptake and the development of herd immunity. ${ }^{4}$ Moreover, this impact can only be 
achieved in the context of continued preventative strategies for all individuals in the community recommended by the WHO. These strategies include high compliance with good personal hand hygiene, wearing of face masks, physical distancing of at least $1 \mathrm{~m}$ between individuals and staying at home. ${ }^{5}$

Several countries in Asia like China, Indonesia, Singapore and Malaysia took strict measures by imposing lockdown measures. ${ }^{6}$ Malaysia implemented a movement control order (MCO) from March to June 2020, ${ }^{7}$ and Singapore had a circuit breaker from April to June $2020^{8}$ to shut workplaces, schools and other social interaction. However, lifting of lockdown measures has differing effectiveness among Asian countries-Malaysia saw a spike in cases and reimplemented MCO in 13 January 2021 which extended to 18 February $2021,{ }^{9}$ while Singapore's cases remained low. ${ }^{10}$

Pandemics have ravaged the world since time immemorial, and many studies have looked at the correlation of how knowledge, attitude and practice (KAP) of the public to preventative measure are correlated to compliance with precautionary measures in infectious disease. ${ }^{10-12}$ Several existing literatures have also demonstrated that KAP of COVID-19 are significantly associated with protective behaviour which can play a major role in the prevention and control of infectious diseases in countries such as Malaysia, ${ }^{13}$ Hong Kong ${ }^{14}$ and China. ${ }^{12}$ However, this is the first multinational quantitative cross-sectional survey to assess the KAP of personal hygiene and physical distancing among Asian countries. We aim to evaluate the factors that are associated with high compliance to personal hygiene and physical distancing. In our study, compliance was divided into high and low categories where an arbitrary cut-off scores of above 75th percentile based on the practice questions were classified as high. A cut-off score of above 75 th percentile was chosen instead of 50th percentile so as to have a more conservative estimate of compliance.

We also aim to compare the differences in KAP between Southeast Asia (SEA) and East Asia (EA) which are economically and culturally different at baseline. For example, in Hong Kong, Japan and South Korea, the habit of mask wearing by people with respiratory conditions was already widespread before the pandemic. After months of counselling the public against wearing face coverings unless they were unwell, Singapore's Government made it mandatory for everyone to wear one outside from April 2020, and provided reusable cloth masks to the entire population. ${ }^{15}$

Non-pharmaceutical measures are useful in curbing the epidemic peak of COVID-19, ${ }^{12-14}$ and we hypothesise that its sustainability even after the development of vaccines requires good KAP on these measures. For improvement of strategy effectiveness, it is important to survey public knowledge, perceptions and behaviours to identify the barriers and gaps to guide existing studies ${ }^{4}$ on public health initiatives to encourage compliance with nonpharmaceutical measures as the response to COVID-19 has underscored the need for governments to improve their outbreak preparedness and response.

\section{METHODOLOGY}

\section{Study design and recruitment}

This was a cross-sectional multinational study conducted in Asia from May to June 2020 and subjects aged 21 years and above were invited to participate in an anonymised survey through social media platforms such as Facebook ads, Instagram and WhatsApp, as well as through word of mouth and electronic mail.

The selection of study sample was done through convenience sampling with demographics compared with the World Bank data to assess if the cohort was representative. The larger the target sample size, the higher the external validity and the greater the generalisability of the study. This study aimed to maximise reach and gather data from as many respondents as possible through the platforms.

\section{Patient and public involvement statement}

Patients or the public were involved in the design, or conduct, or reporting or dissemination plans of our research.

\section{Study instrument}

The secured survey was conducted via mySurvey, an online survey platform hosted by the National University of Singapore (Verint Systems, New York, USA). The survey link is https://mysurvey.nus.edu.sg/EFM/ se/543BE5C2182BB4F7 (online supplemental file 1). The initial questionnaire was developed in the English language. Translation to other languages was performed by Google Translate with review by native speakers of the language (including Simplified and Traditional Chinese, Indonesian Bahasa, Malay, Bengali and Korean). It was subsequently translated back to English for review by the local questionnaire development team to resolve any discrepancies in language. Our questionnaire was grouped into four main sections: (1) demographics, (2) KAP on personal hygiene; (3) KAP on physical distancing and (4) the biopsychosocial impact on participants.

Questions on a five-point Likert scale (never, seldom, $50 \%$ of the time, most of the time, always) were designed to assess how often participants were compliant to good personal hygiene and physical distancing practice. To assess the psychological impact of COVID-19, the Mental Health Continuum-Short Form (MHC-SF) ${ }^{16}$ was used. The MHC-SF is a 14-item questionnaire that assesses three components (ie, emotional, social and psychological) of well-being and can also be used to classify participants as flourishing and not-flourishing. ${ }^{17}$ For each question, participants were asked to rate their feelings in the past month on a six-point Likert scale (never, once or twice a month, about once a week, two or three times a week, almost every day, every day). This assessment tool has been validated in many different countries such as Italy, South Korea and South Africa. ${ }^{18-20}$ 
The study is aligned with the STROBE (Strengthening the Reporting of Observational Studies in Epidemiology) guidelines. The checklist can be found in online supplemental file 2 .

\section{Statistical analysis}

Statistical analysis was performed using SPSS V.26 (IBM SPSS Statistics). Differences in responses to the questionnaire between the two regions were assessed using $\chi^{2}$ test for questions with categorical outcomes and univariate analysis for questions with continuous outcomes. Bonferroni correction was applied. Subjects' compliance was divided into high and low categories, where scores above 75th percentile were classified as high. Subjects' compliance with physical distancing measures were derived from the questions 'How often do you wash your hands with soap or alcohol-based disinfectant a day?', 'Do you wash your hands before and after handling food?', 'Do you cover your mouth when you sneeze or cough?', 'Do you wear a mask in public?', 'Do you AVOID touching your eyes nose and mouth during COVID-19 pandemic?', 'Do you avoid shaking hands?', 'Do you wipe surfaces and objects with disinfectant regularly?' and 'Do you avoid standing or sitting close to people?', where subjects who responded to all of the questions with hand washing for five to six times per day or seven or more times per day and most of the time or always for the other questions were classified as having high compliance, while the rest of the participants were classified as having low compliance. Univariate and multivariate logistic regression (including factors that were significant in univariate analysis) was carried out. The statistical significance level was set at $\mathrm{p}<0.05$.

Reliability analysis (online supplemental file 1; figure 1 and 2) was conducted by assessing Cronbach's alpha coefficient with recommended cut-off $\alpha>=0.7$ to assess internal consistency. A three-factor confirmatory factor analysis (CFA) was conducted for the questions under MHC-SF using the software: R, lavaan package with Raykov's rho using recommended cut-off $\omega>=0.7$. Fit measurement indices and recommended cut-off values: $\chi^{2}$-cut-off: $\mathrm{p}>0.05$; standard root mean square-cut-off: $<=0.08$; root mean square error of approximation-cutoff: $<=0.08$ (90\% CI); Comparative Fit Index (CFI) - cutoff: $>=0.95$. Exploratory factor analysis which involves the following was conducted with software: $\mathrm{R}$, psych package: Bartlett test and Kaiser-Meyer-Olkin (KMO) test to check if the factor analysis is appropriate; Scree plot and parallel analysis to identify the number of factors; factor analysis with minimum residual method as well as oblique rotation allowing for covariance between factors; filter items whose loading larger than 0.4 and no cross-loading.

\section{Ethics}

As no individual identifiable information was obtained during the questionnaire, confidentiality and anonymity were maintained. The National Healthcare Group
Domain Specific Review Board reference number for this study is $2020 / 00470$.

\section{RESULTS}

\section{Comparison of demographic variables between participants} from EA and SEA

Among the 2574 responses obtained, 762 (29.6\%) participants were from EA (China, Hong Kong, Taiwan, South Korea, Macau and Japan) and $1812(70.4 \%)$ were from SEA (Singapore, Indonesia, Brunei, Cambodia, Myanmar, Philippines, Thailand, Vietnam and Malaysia). The proportion of older participants above 50 years old, as well as male participants were significantly higher for EA as compared with SEA (23.4\% vs $19.2 \% ; 47.5 \%$ vs $32.7 \%$, respectively, $\mathrm{p}<0.01)$. EA population was dominated by the Chinese (75.6\%) and Korean (21.5\%), while the SEA population was dominated by the Chinese $(51.5 \%)$ and Malay $(25.4 \%, \mathrm{p}<0.01)$ (table 1$)$.

In table 1 , most participants from EA were currently based in Hong Kong (37.4\%), Taiwan $(23.1 \%)$ and South Korea $(21.7 \%)$, while participants from SEA were based in Indonesia (25.4\%), Malaysia (18.0\%) and Singapore $(54.8 \%, \mathrm{p}<0.01)$. There was a higher proportion of countries with upper-middle income in EA compared with SEA $(39.1 \%$ vs $18.2 \%, \mathrm{p}<0.01)$. Similarly, a greater proportion of participants from EA had household incomes of more than US\$10000 (42.4\% vs $23.0 \%, \mathrm{p}<0.01)$ and stayed in private apartment or condominium $(43.4 \%$ vs $20.6 \%$, $\mathrm{p}<0.01)$ compared with SEA. Family sizes were significantly smaller (1-4 members) in EA as compared with SEA $(79.7 \%$ vs $62.5 \%, \mathrm{p}<0.01)$.

A higher proportion of participants from the SEA had tertiary education compared with those from EA $(80.2 \%$ vs $70.6 \%, \mathrm{p}<0.01)$. A greater proportion of employees from SEA were healthcare workers $(52.0 \%$ vs $43.0 \%, \mathrm{p}<0.01)$ and had to interact physically with people ( 68.6 vs $59.1 \%$, $\mathrm{p}<0.01)$ than those from EA. There was a higher proportion of participants diagnosed with COVID-19 (1.9\% vs $0.7 \%, \mathrm{p}=0.034)$ and had friends or family members with COVID-19 in SEA than in EA $(10.0 \%$ vs $4.7 \%, \mathrm{p}<0.01$, respectively).

There were no significant differences between participants from EA and SEA in employment status $(74.5 \%$ vs $74.2 \%)$, working from home arrangements $(36.9 \%$ vs $37.1 \%)$, having older people or children at home $(47.0 \%$ vs $44.9 \%)$ and having a serious medical condition $(12.1 \%$ vs $12.6 \%)$.

Overall reliability, exploratory and confirmatory factor analysis The overall reliability for the questions under MHC-SF was Cronbach's alpha $(\alpha)=0.94$, which illustrates great overall internal consistency. From the three-factor CFA for MHC-SF, all the $\alpha, \omega>=0.7$, which shows high internal consistency in every single construct (online supplemental figures 1, 2 and table 1). The overall reliability for the questions under personal hygiene and physical distancing showed $\alpha=0.74$, which illustrated acceptable 
Open access

Table 1 Demographic variables and responses to the survey questions on knowledge, attitude and practice of personal hygiene and physical distancing during COVID-19

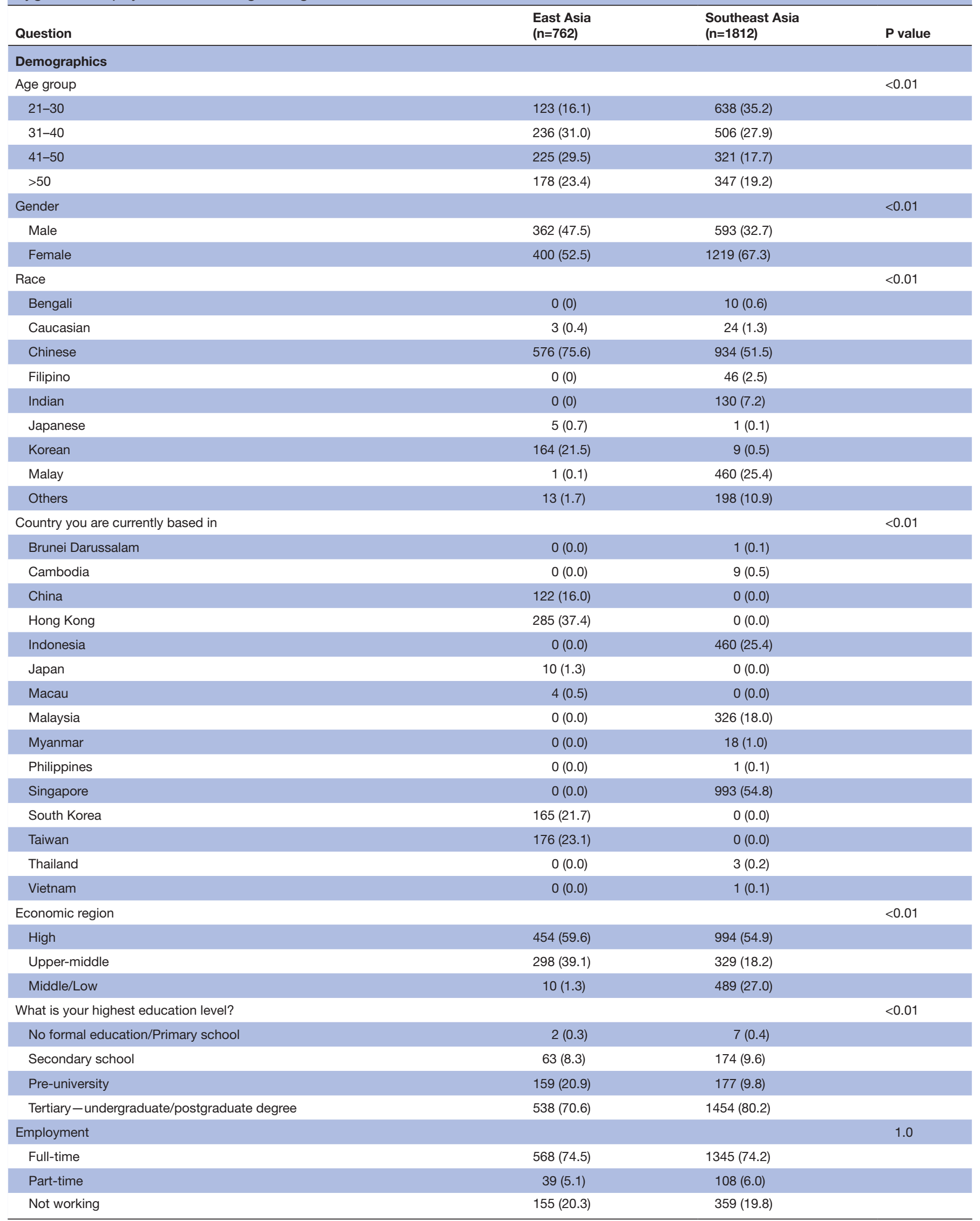

Continued 
Table 1 Continued

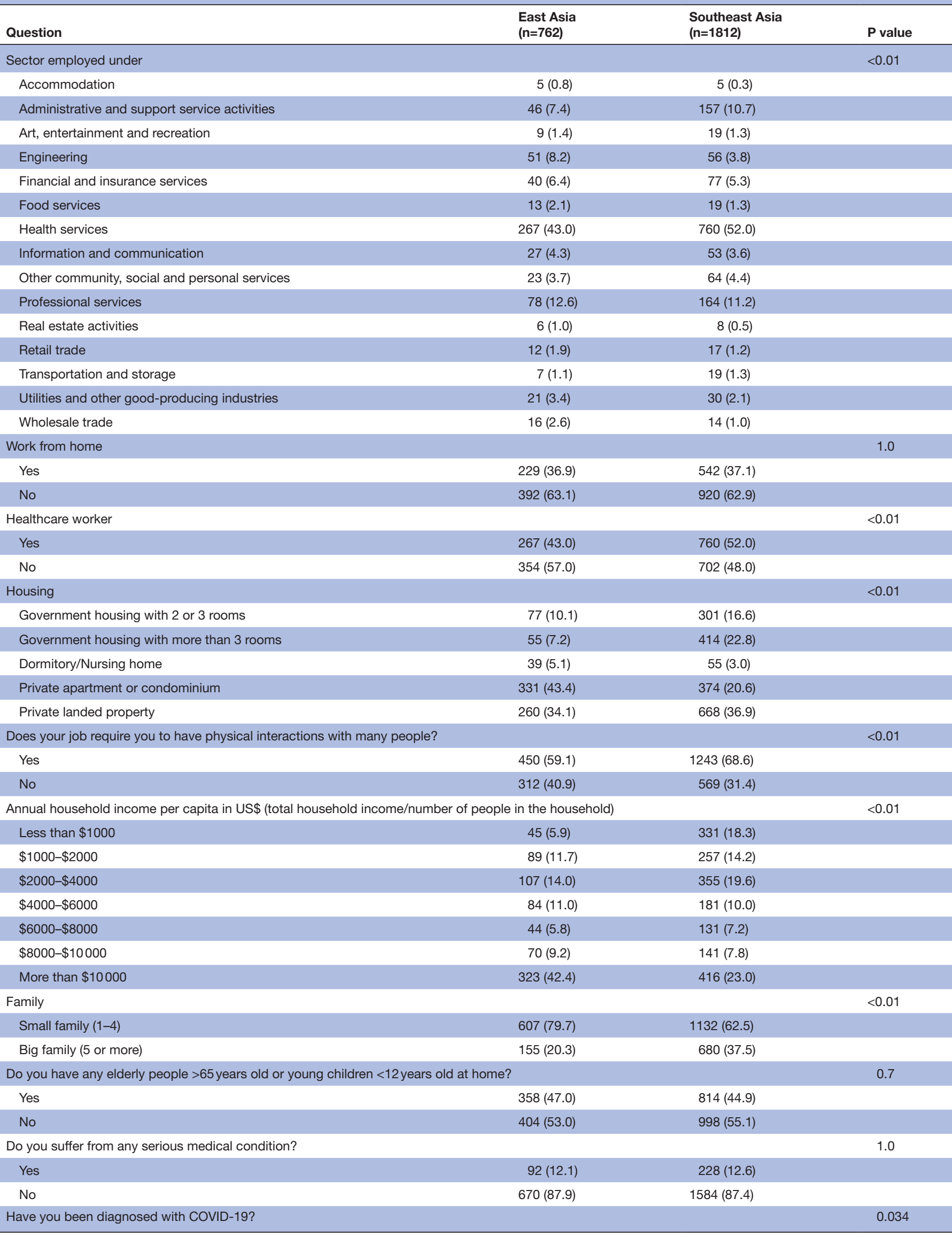


Open access

Table 1 Continued

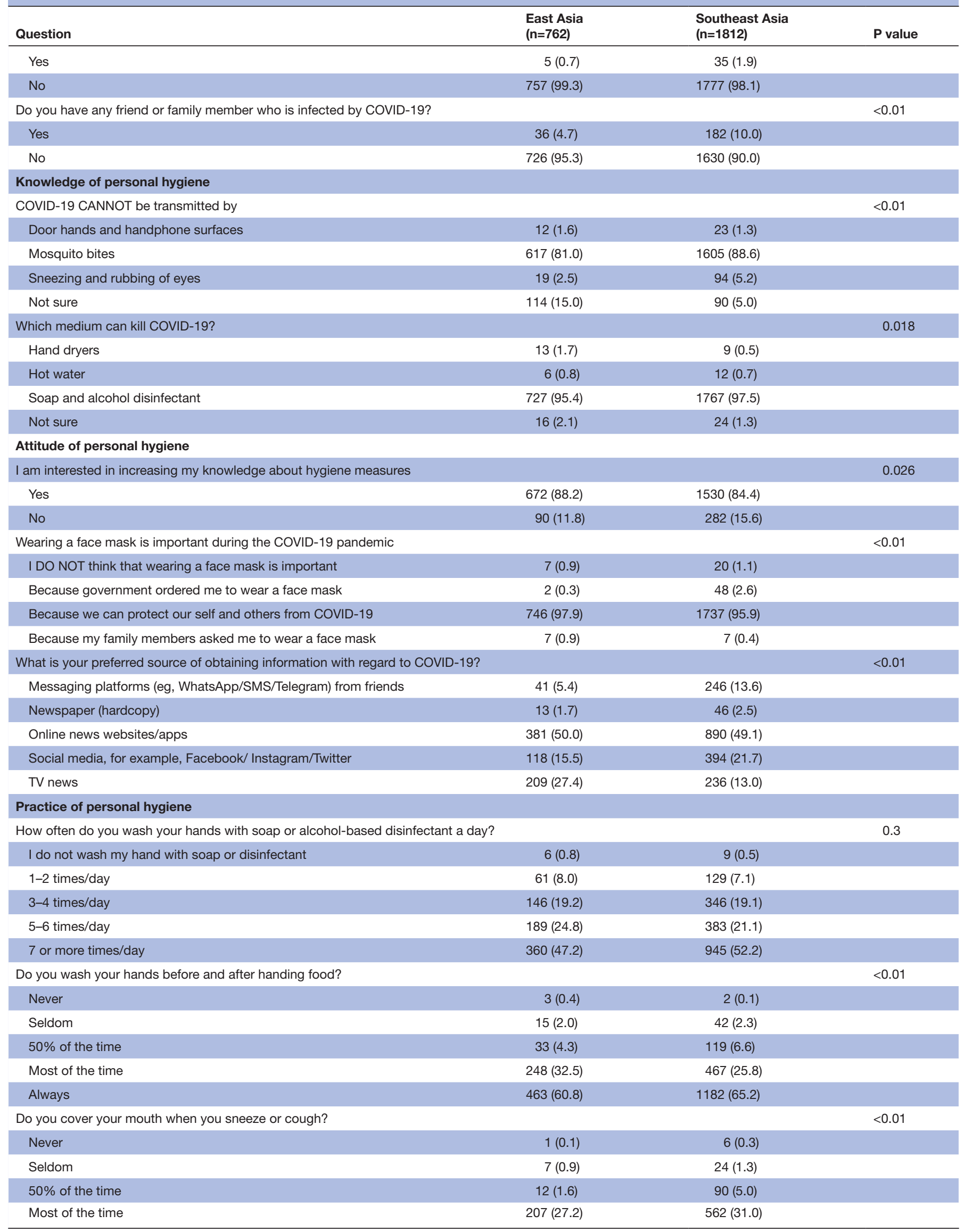


Table 1 Continued

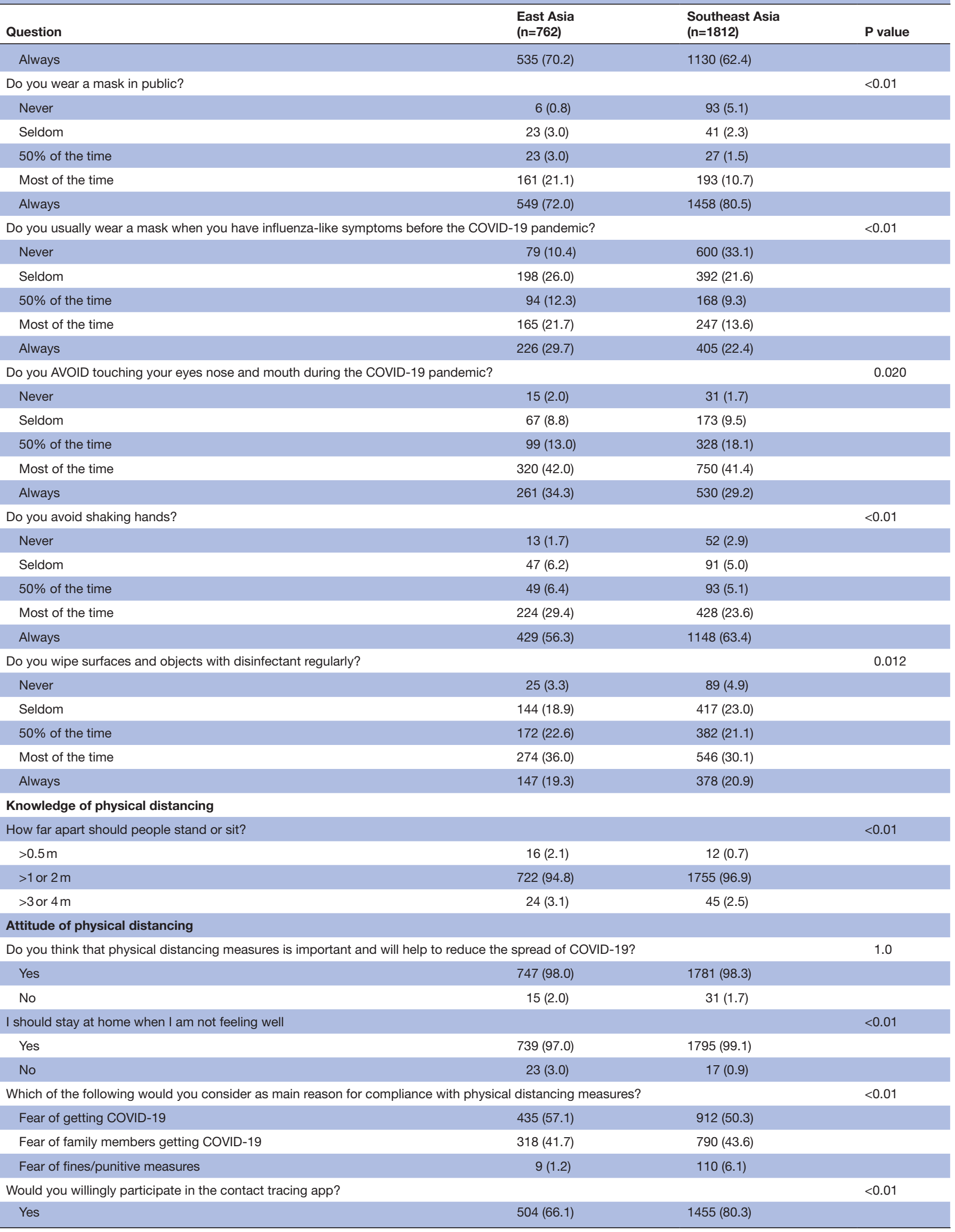


Open access

Table 1 Continued

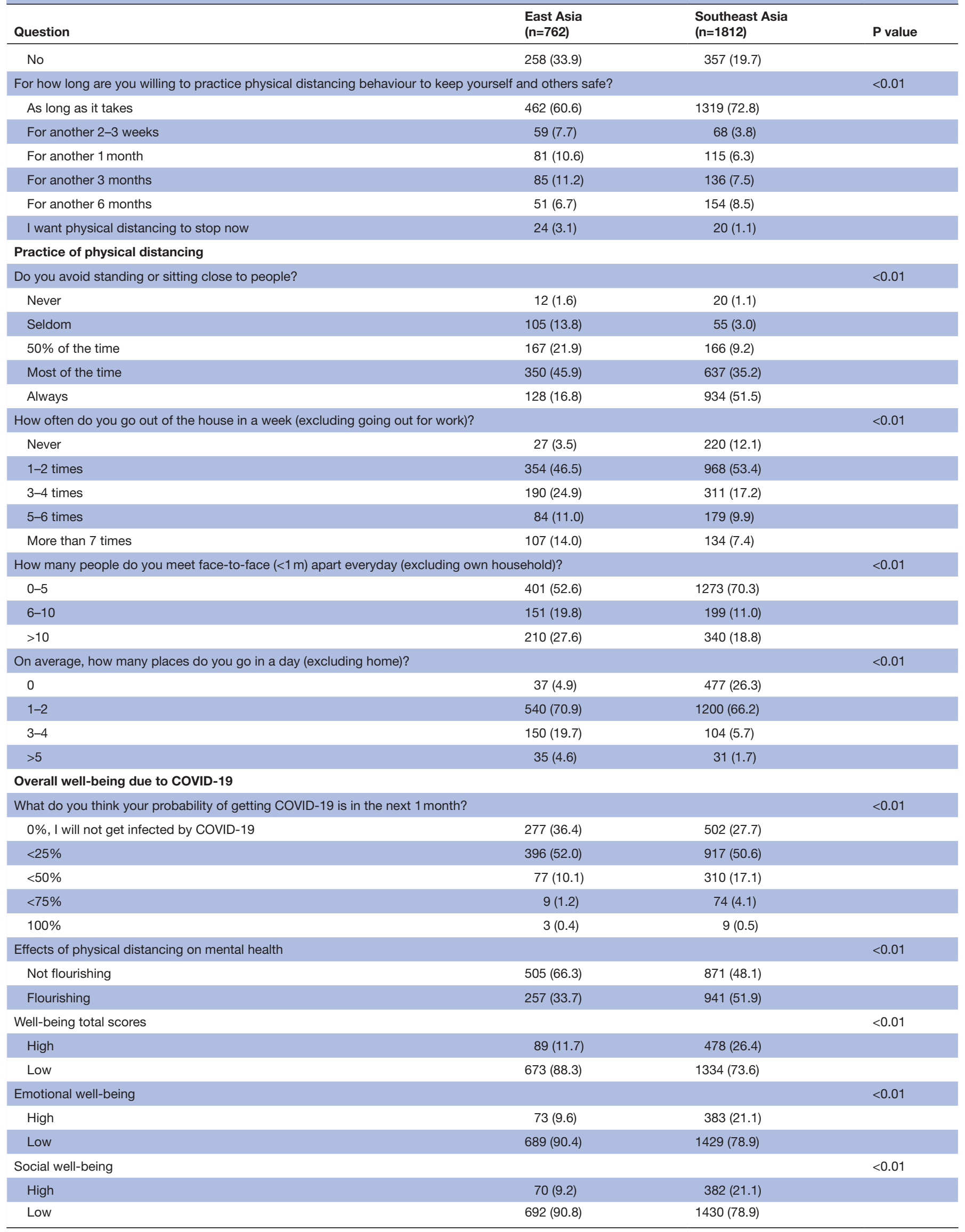


Table 1 Continued

\begin{tabular}{llr}
\hline Question & $\begin{array}{l}\text { East Asia } \\
(\mathbf{n = 7 6 2 )}\end{array}$ & $\begin{array}{l}\text { Southeast Asia } \\
(\mathbf{n = 1 8 1 2})\end{array}$ \\
\hline Psychological well-being & & $\mathbf{P}$ value \\
High & $122(16.0)$ & $507(28.0)$ \\
Low & $640(84.0)$ & $1305(72.0)$ \\
\hline
\end{tabular}

overall internal consistency. Bartlett ( $\mathrm{p}$ value $<0.001$ ) and KMO $(>0.80)$ tests suggested that the data are suitable for factor analysis. Scree suggested two principal components. From the two-factor CFA for personal hygiene and physical distancing questions, the construct of personal hygiene shows great internal consistency, while the construct of physical distancing has limited internal consistency which may be attributed to the small number of items in the construct (online supplemental figures 1 , 2 and table 2).

\section{Knowledge, attitude and practice of personal hygiene Knowledge}

A higher proportion of participants from SEA were aware that COVID-19 could not be transmitted by mosquito bites $(88.6 \%$ vs $81.0 \%, \mathrm{p}<0.01)$ and soap and disinfectant can kill COVID-19 (97.5\% vs 95.4\%, $\mathrm{p}=0.018)$ compared with those from EA.

\section{Attitude}

A higher proportion of participants from EA was interested in increasing their knowledge about good hygiene measures $(88.2 \%$ vs $84.4 \%, \mathrm{p}=0.026)$ and understood that wearing a face mask is important during the COVID-19 pandemic as it can protect themselves and their family $(97.9 \%$ vs $95.9 \%, \mathrm{p}<0.01)$ as compared with SEA. A greater proportion of participants from EA preferred obtaining information on COVID-19 from official news channels (newspaper, online news website/apps and TV news) $(79.1 \%$ vs $64.6 \%, \mathrm{p}<0.01)$.

\section{Practice}

A greater proportion of participants from SEA always washed their hands before and after handling food $(65.2 \%$ vs $60.8 \%)$, wore a mask in public $(80.5 \%$ vs $72.0 \%)$, avoided shaking hands $(63.4 \%$ vs $56.3 \%)$ and wiped surfaces and objects with disinfectant regularly $(20.9 \%$ vs $19.3 \%, \mathrm{p}<0.05)$ as compared with subjects from EA. Interestingly, there was a higher proportion of participants from EA who always cover their mouths when sneezing or coughing, wear a mask when they had influenza-like symptoms before the COVID-19 pandemic and avoided touching their eyes, noses and mouths during the COVID-19 pandemic $(70.2 \%, 29.7 \%, 34.3 \%$, respectively) compared with SEA $(62.4 \%, 22.4 \%, 29.2 \%$, respectively, $\mathrm{p}<0.05)$. There were no significant differences between proportion of participants from EA and SEA who washed their hands with soap or alcohol-based disinfectant frequently (at least seven times per day: $47.2 \%$ vs $52.2 \%$ ).

\section{Knowledge, attitude and practice of physical distancing Knowledge}

A higher proportion of participants from SEA felt that people should stand or sit more than 1 or $2 \mathrm{~m}$ apart as compared with those from EA $(96.9 \%$ vs $94.8 \%, \mathrm{p}<0.01)$.

\section{Attitudes}

A greater proportion of participants from SEA felt that they should stay home when not feeling well, were willing to participate in the contact tracing application and were willing to practise physical distancing as long as it takes $(99.1 \%, 80.3 \%, 72.8 \%)$ as compared with those from EA $(97.0 \%, 66.1 \%, 60.6 \%, \mathrm{p}<0.01)$.

There were differences in reasons for compliance between SEA and EA; a higher proportion of participants from EA stated that fear of getting COVID-19 was the main reason for compliance with physical distancing measures $(57.1 \%$ vs $50.3 \%)$, while a higher proportion from SEA stated fear of family members getting COVID-19 as the main reason $(43.6 \%$ vs $41.7 \%, \mathrm{p}<0.01)$.

There were no significant differences between the proportion of participants from EA and SEA who believed in the importance of physical distancing measures in reducing the spread of COVID-19 (98.0\% vs $98.3 \%)$.

\section{Practices}

A higher proportion of participants from SEA always avoided standing or sitting close to people compared with EA $(51.5 \%$ vs $16.8 \%, \mathrm{p}<0.01)$. Similarly, more subjects from EA went out of the house more than seven times a week ( $14.0 \%$ vs $7.4 \%)$, met more than 10 people not from their household face-to-face every day $(27.6 \%$ vs $18.8 \%)$ and went to more than five places except home $(4.6 \%$ vs $1.7 \%, \mathrm{p}<0.01)$.

\section{Overall well-being due to COVID-19}

In figure 1, a higher proportion of participants from EA felt that they have the lower chance $(<25 \%)$ of getting infected by COVID-19 $(88.4 \%)$ than those from SEA (78.3\%, p<0.01). A greater proportion of participants from SEA were flourishing ( $51.9 \%$ vs $33.7 \%, \mathrm{p}<0.01)$ and had better overall well-being (mean \pm SD: $46.3 \pm 14.9$ vs $41.1 \pm 14.2, \mathrm{p}<0.01$ ), emotional (based on happiness,

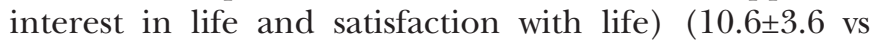
$9.30 \pm 3.4, \mathrm{p}<0.01$ ), social (based on feelings on social contribution, integration, actualisation and coherence) $(15.3 \pm 6.2$ vs $13.2 \pm 5.9, \mathrm{p}<0.01)$ and psychological (based on feelings on self-acceptance, environmental mastery, positive relations with others, personal growth, autonomy 


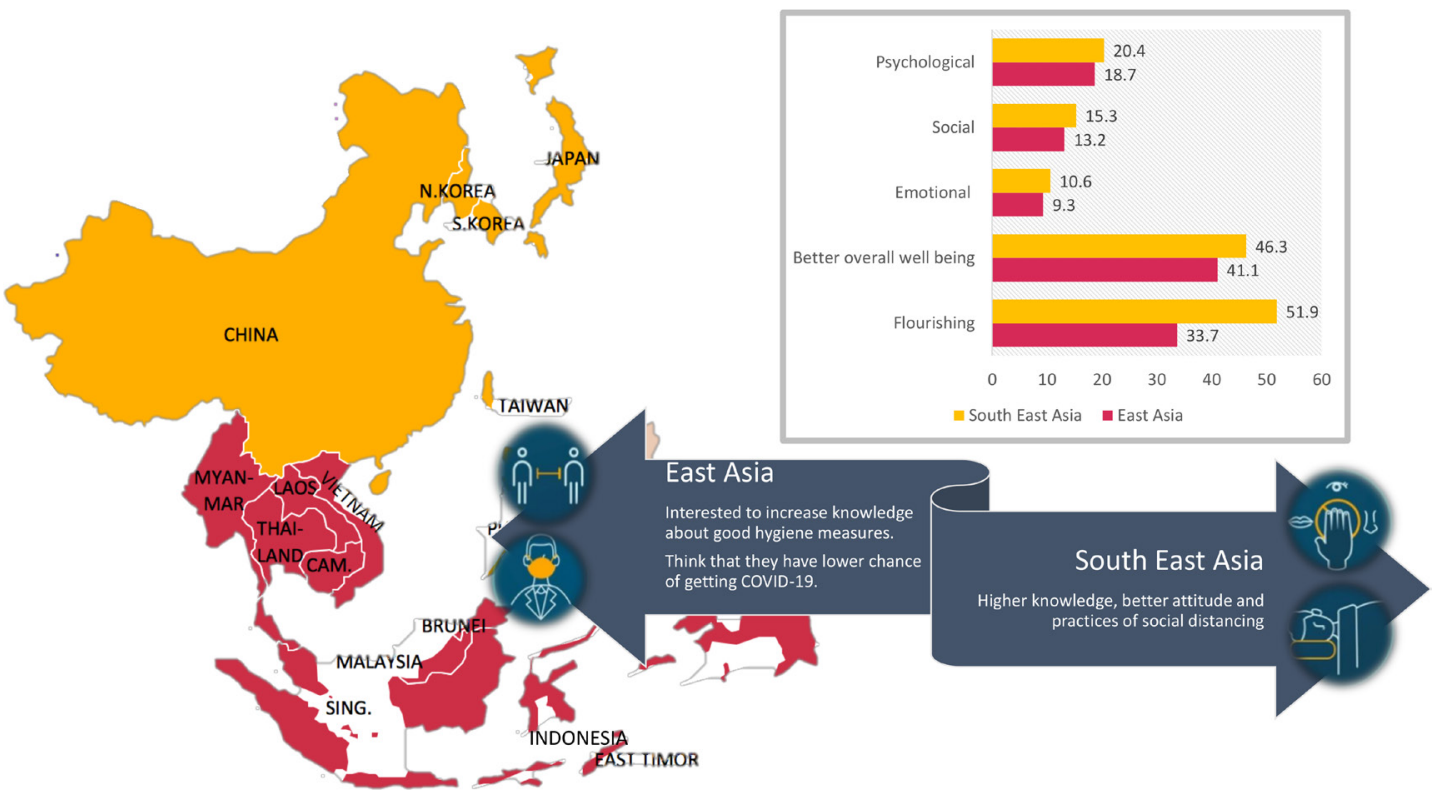

Figure 1 Differences between Southeast Asia and East Asia.

and purpose in life) $(20.4 \pm 6.8$ vs $18.7 \pm 6.6, \quad \mathrm{p}<0.01)$ well-being.

\section{Factors associated with compliance}

In table 2, participants from EA and SEA were further divided into high compliant and low compliant subgroups. In univariate analysis, being of older age (31-40 years old: OR $1.2695 \%$ CI (1.01 to 1.57 ); 41-50 years old: OR $1.4995 \%$ CI (1.18 to 1.89 ); more than 50 years old: OR $1.4195 \% \mathrm{CI}$ (1.11 to 1.79)), being a healthcare worker (OR $1.8395 \%$ CI (1.53 to 2.20)) and having a job requiring physical interaction with many people (OR $1.6395 \%$ CI (1.36 to 1.96)) were significantly associated with high compliance (online supplemental table $3)$. Participants who responded they should stand at least more than 1 or $2 \mathrm{~m}$ apart (OR $6.2895 \%$ CI (1.49 to 26.53)) and more than 3 or $4 \mathrm{~m}$ apart (OR $8.3695 \%$ CI (1.83 to 38.11$)$ ) were significantly associated with high compliance compared with those who responded that will stand $<0.5 \mathrm{~m}$ apart. Participants who were willing to participate in the contact tracing application (OR 1.45 95\% CI (1.19 to 1.78$)$ ) and wore masks when they had influenza-like symptoms before the COVID-19 epidemic (seldom: OR $1.3795 \%$ CI (1.04 to 1.81$) ; 50 \%$ of the time: OR $2.0795 \%$ CI (1.49 to 2.87$)$; most of the time: OR $3.2795 \%$ CI (2.48 to 4.32 ); always: OR $5.3395 \%$ CI (4.14 to 6.85$)$ ) were significantly associated with high compliance. Participants who preferred official news channels such as online news websites/applications (OR $1.3795 \%$ CI (1.03 to 1.82$)$ ) or TV news (OR $1.4095 \%$ CI (1.01 to 1.94$)$ ) were significantly associated with high compliance. Participants who had high emotional (OR $2.3695 \%$ CI (1.95 to 2.86$)$ ), social (OR $2.2095 \%$ CI (1.79 to 2.70)) and psychological well-being (OR 2.12 95\% CI (1.72 to 2.61$)$ ) were significantly associated with high compliance. Better attitudes towards personal hygiene and physical distancing were positively correlated with high compliance $(\mathrm{R}=0.06$ and 0.13 , respectively, $\mathrm{p}<0.01)$. There were no associations between geographical location and high compliance.

\section{Barriers associated with low compliance}

Male gender (OR $0.5895 \%$ CI (0.48 to 0.69$)$ ), being of Korean ancestry (OR $0.2695 \%$ CI $(0.07$ to 0.96$)$ ) and staying in government housing with more than three rooms (OR $0.7495 \%$ CI $(0.55$ to 0.98$)$ ) were significantly associated with poor compliance. Lack of knowledge on the potential severity of COVID-19 such as fear of fines or punitive measures as the main reason for compliance with physical distancing measures (OR $0.4395 \%$ CI $(0.27$ to 0.69$))$ as compared with the fear of getting COVID-19 were significantly associated with poor compliance. As compared with those who will practise physical distancing for as long as necessary, subjects who were willing to practise physical distancing behaviour for another $2-3$ weeks (OR $0.5295 \%$ CI $(0.34$ to 0.81$)$ ) or another month (OR $0.6795 \%$ CI ( 0.48 to 0.93 ) ) or wanted physical distancing to stop (OR 0.14 $95 \%$ CI (0.04 to 0.44$)$ ) were significantly associated with poor compliance. With reference to those who never went out of the house in a week except for work, subjects who went out three to four times (OR $0.6095 \%$ CI $(0.43$ to 0.83 )), five to six times (OR $0.6195 \%$ CI $(0.42$ to $0.89)$ ) and seven or more times (OR $0.6895 \%$ CI $(0.46$ to 0.99$))$ were significantly associated with poor compliance. Subjects who went to three to four places in a day (OR $0.6695 \%$ CI (0.47 to 0.92)) as compared with staying at home were significantly associated with poor compliance. Subjects who believed their probability of getting COVID-19 in the next 1 month was less than 25\% (OR $0.7095 \%$ CI (0.58 to 0.84$)$ ) and less than $50 \%$ (OR $0.7695 \%$ CI (0.59 to 0.98$))$ as compared with $0 \%$ were significantly associated with poor compliance. 
Table 2 Multivariate analysis of factors associated with high level of compliance

Question

OR $(95 \% \mathrm{Cl})$

$P$ value

Age group

21-30 (ref)

$31-40$

1.27 (0.97 to 1.68$)$

0.1

$41-50$

1.79 (1.31 to 2.43$) \quad<0.001$

$>50$

1.68 (1.19 to 2.37 )

$<0.01$

Male gender (ref: female)

0.61 (0.49 to 0.77$)$

$<0.001$

Race

Bengali (ref)

Caucasian

0.65 (0.08 to 5.08$) \quad 0.7$

Chinese

0.84 (0.15 to 4.69$) \quad 0.8$

Filipino

2.24 (0.35 to 14.35$) \quad 0.4$

Indian

1.01 (0.18 to 5.81$) \quad 1.0$

Japanese

0.29 (0.02 to 5.11$) \quad 0.4$

Korean

0.50 (0.08 to 3.03$) \quad 0.5$

Malay

$1.02(0.18$ to 5.69$) \quad 1.0$

Others

0.76 (0.14 to 4.31$) \quad 0.8$

Southeast Asia (ref: East Asia)

0.84 (0.61 to 1.14$) \quad 0.3$

Healthcare worker (ref: no)

$1.59(1.27$ to 1.99$) \quad<0.001$

Housing

Government housing with 2 or 3 rooms (ref)

Government housing with more than 3 rooms

Dormitory/Nursing home

0.98 (0.69 to 1.41$) \quad 0.9$

Private apartment or condominium

$0.76(0.38$ to 1.50$) \quad 0.4$

Private landed property

$1.02(0.73$ to 1.43$) \quad 0.9$

Does your job require you to have physical interactions with many people? (ref: no)

1.08 (0.78 to 1.51$) \quad 0.6$

What is your preferred source of obtaining information with regard to COVID-19?

Messaging platforms (eg, WhatsApp/SMS/Telegram) from friends (ref)

Newspaper (hardcopy)

$1.22(0.94$ to 1.57$)$

0.1

Online news websites/apps

Social media, for example, Facebook/Instagram/Twitter

1.25 (0.55 to 2.87$) \quad 0.6$

TV news

$1.73(1.21$ to 2.49$) \quad<0.01$

1.68 (1.13 to 2.50$) \quad 0.01$

$1.33(0.88$ to 2.02$) \quad 0.2$

Do you usually wear a mask when you have influenza-like symptoms before the COVID-19 pandemic?

$\begin{array}{lrr}\text { Never (ref) } & 1.50(1.09 \text { to } 2.07) & 0.014 \\ \text { Seldom } & 1.99(1.35 \text { to } 2.94) & <0.001 \\ 50 \% \text { of the time } & 3.32(2.35 \text { to } 4.68) & <0.001 \\ \text { Most of the time } & 5.09(3.71 \text { to } 6.98) & <0.001\end{array}$

How far apart should people stand or sit?

\begin{tabular}{|c|c|c|}
\hline \multicolumn{3}{|c|}{$>0.5 \mathrm{~m}$ (ref) } \\
\hline$>1$ or $2 \mathrm{~m}$ & 5.09 (1.08 to 24.01$)$ & 0.040 \\
\hline$>3$ or $4 \mathrm{~m}$ & 7.05 (1.32 to 37.67$)$ & 0.022 \\
\hline
\end{tabular}

Which of the following would you consider as main reason for compliance with physical distancing measures?

\section{Fear of getting COVID-19 (ref)}

Fear of family members getting COVID-19

Fear of fines/punitive measures

Would you willingly participate in the contact tracing app? (ref: no)

$\begin{array}{ll}0.95(0.77 \text { to } 1.18) & 0.6 \\ 0.85(0.48 \text { to } 1.53) & 0.6 \\ 1.12(0.87 \text { to } 1.44) & 0.4\end{array}$

Continued 


\begin{tabular}{|c|c|c|}
\hline Question & OR $(95 \% \mathrm{Cl})$ & P value \\
\hline \multicolumn{3}{|c|}{ For how long are you willing to practice physical distancing behaviour to keep yourself and others safe? } \\
\hline \multicolumn{3}{|l|}{ As long as it takes (ref) } \\
\hline For another $2-3$ weeks & $0.62(0.37$ to 1.03$)$ & 0.1 \\
\hline For another 1 month & 0.75 (0.50 to 1.12$)$ & 0.2 \\
\hline For another 3 months & $0.84(0.58$ to 1.21$)$ & 0.3 \\
\hline For another 6 months & $0.79(0.54$ to 1.16$)$ & 0.2 \\
\hline I want physical distancing to stop now & 0.15 (0.04 to 0.53$)$ & $<0.01$ \\
\hline \multicolumn{3}{|c|}{ How often do you go out of the house in a week (excluding going out for work)? } \\
\hline \multicolumn{3}{|l|}{ Never (ref) } \\
\hline $1-2$ times & $0.73(0.50$ to 1.07$)$ & 0.1 \\
\hline 3-4 times & 0.61 (0.39 to 0.94$)$ & 0.025 \\
\hline $5-6$ times & $0.48(0.29$ to 0.78$)$ & $<0.01$ \\
\hline More than 7 times & 0.59 (0.35 to 0.99$)$ & 0.048 \\
\hline \multicolumn{3}{|c|}{ On average, how many places do you go in a day (excluding home)? } \\
\hline \multicolumn{3}{|l|}{0 (ref) } \\
\hline $1-2$ & $0.93(0.69$ to 1.26$)$ & 0.7 \\
\hline $3-4$ & $0.65(0.41$ to 1.03$)$ & 0.1 \\
\hline$>5$ & 1.28 (0.64 to 2.60$)$ & 0.5 \\
\hline \multicolumn{3}{|c|}{ What do you think your probability of getting COVID-19 is in the next 1 month? } \\
\hline \multicolumn{3}{|c|}{ 0\%, I will not get infected by COVID-19 (ref) } \\
\hline$<25 \%$ & 0.88 (0.69 to 1.13$)$ & 0.3 \\
\hline$<50 \%$ & 0.80 (0.58 to 1.10$)$ & 0.2 \\
\hline$<75 \%$ & 0.86 (0.50 to 1.50$)$ & 0.6 \\
\hline $100 \%$ & 0.81 (0.16 to 4.13$)$ & 0.8 \\
\hline Emotional well-being (ref: low) & 1.54 (1.12 to 2.12$)$ & $<0.01$ \\
\hline Social well-being (ref: low) & 1.22 (0.88 to 1.69$)$ & 0.2 \\
\hline Psychological well-being (ref: low) & 1.39 (1.04 to 1.87$)$ & 0.026 \\
\hline
\end{tabular}

Independent risk factors associated with compliance

Being older than 40 years old (41-50 years old: AdjOR $1.7995 \%$ CI (1.31 to 2.43); more than 50 years old: AdjOR $1.6895 \%$ CI (1.19 to 2.37)), being in a healthcare occupation (AdjOR 1.59 95\% CI (1.27 to 1.99)), having safe distancing practices such as standing more than 1 or $2 \mathrm{~m}$ apart (AdjOR 5.09 95\% CI (1.08 to 24.01)) or more than 3 or $4 \mathrm{~m}$ apart (AdjOR $7.0595 \%$ CI (1.32 to 37.67)), wearing a mask when they had influenza-like symptoms before the COVID-19 pandemic, preferring online news channels such as online news websites/applications (AdjOR 1.73 95\% CI (1.21 to 2.49)) and social media (AdjOR 1.68 95\% CI (1.13 to 2.50$)$ ) as sources of obtaining information about COVID-19 and high emotional (AdjOR 1.54 95\% CI (1.12 to 2.12)) and psychological well-being (AdjOR 1.39 95\% CI (1.04 to 1.87)) were independent factors associated with high compliance (table 2).

On the other hand, being of male gender (AdjOR 0.61 95\% CI (0.49 to 0.77)), unwillingness to continue with physical distancing (AdjOR 0.15 95\% CI (0.04 to 0.53)), going out of the houses frequently (three to four times: AdjOR $0.6195 \%$ CI (0.39 to 0.94); five to six times: AdjOR
$0.4895 \%$ CI (0.29 to 0.78); more than seven times: AdjOR $0.5995 \%$ CI $(0.35$ to 0.99$)$ ) were significantly associated with poor compliance. There were no associations between geographical location and compliance.

\section{DISCUSSION}

Four countries in Asia took strict measures by imposing lockdown restrictions. ${ }^{21}$ During our survey period in May-June 2020, lockdowns were imposed such as Singapore had a circuit breaker and Malaysia had an MCO. On the other hand, South Korea and China started to ease their restrictions in this period. In order to effectively manage the spread and social effects of this pandemic, it is imperative to understand the factors associated with high and low compliance behaviours to ease progressive exit from lockdown. ${ }^{22}$

\section{Differences in KAP between EA and SEA}

Findings (online supplemental table 4) from this study indicate that subjects from both SEA and EA are highly knowledgeable in personal hygiene and physical 
distancing measures. However, a greater proportion of subjects from SEA felt that they should stay at home when they are not feeling well, are more willing to participate in the contact tracing application and to practise physical distancing as long as it takes. We postulate that this could be because subjects from EA felt they had a lower chance of getting infected by COVID-19 during the survey period. The positive impact of transparency, a better healthcare system, as well as the respective government's handling of the pandemic in its initial months may have built EA's community confidence in having a lower chance of getting infected by COVID-19. South Korea, Japan, Taiwan and Hong Kong were ranked in the top 10 world's most efficient healthcare systems. ${ }^{23}$ During the study period from May to June 2020, new COVID-19 cases in EA were on a declining rate and were already past the peak which occurred between February and March 2020. This was in stark contrast with countries in SEA such as Singapore, which registered record-high COVID-19 cases between late April and May as a result of the spread of COVID-19 among its migrant worker population. Similarly, in other SEA countries such as Indonesia, there was also a rising COVID-19 infection rate during the survey study period, with more than a thousand COVID-19 cases a day on most days in June. The worsening pandemic situation in SEA resulted in subjects being more fearful of COVID-19 and hence more willing to participate in measures to reduce the risk of COVID-19.

\section{Association of well-beings with compliance behaviour in Asia}

Psychological well-being was associated with high compliance in the current study. Unlike emotional well-being, referring to feelings of happiness and life satisfaction, psychological well-being refers to self-realisation. ${ }^{24}$ Interestingly, social well-being, referring to the functioning of the individual within the society, was not a significant factor of compliance. This could possibly suggest that being compliant is more related to feelings of fulfilment and purpose than to community functioning. Previous studies have shown that good health behaviours have been related to positive affect and well-being, similar to the current study. For example, in a Korean study, negative affect from academic stress contributed to poor health behaviours such as drinking alcohol and smoking. ${ }^{25}$ Recent reviews confirm that well-being and positive affect can increase health promotive and illness preventative behaviours. ${ }^{26} 27$ A study across 24 countries in Asia, Africa and America among university students showed that happiness was positively linked to health behaviours such as physical activity. ${ }^{24}$ Higher happiness was associated with lower stress, a healthy diet and exercise in middle-aged Korean adults. ${ }^{28}$ A 2008 longitudinal study showed that psychological well-being predicted health behaviours, such as eating fruits and vegetables, independent of depressive symptoms. ${ }^{29}$ The mechanisms of this should be understood and explored more, but possible suggestions include a boost in self-efficacy, energy, will power and selfcontrol. ${ }^{27}{ }^{29}$ The above results highlight the importance of investigating well-being and adaptive functioning independently of measuring psychopathology in health promotion and compliance.

\section{Factors and barriers to compliance behaviour}

Findings from our study revealed that older age, being in a healthcare occupation and preferring online news and social media as sources of COVID-19 information were significantly associated with high compliance behaviour. Several studies conducted in other Asian countries have indicated high levels of COVID-19 knowledge among the general population and healthcare workers. ${ }^{13}{ }^{30}$ In one study, Malaysians above the age of 50 had higher knowledge scores compared with other age groups in Malaysia, possibly due to a higher risk perception of infection and complications from the disease. ${ }^{13}$ High COVID-19 knowledge scores were significantly associated with a lower likelihood of negative attitudes and potentially dangerous practices towards COVID-19. ${ }^{30}$

It is also postulated that people who use online news have more initiatives to find out more about COVID-19 and hence higher compliance. A case study revealed that Taiwan's novel collaboration between the public and government in the development of online tools for mask rationing with more than 2 million users helped flatten its COVID-19 curve. The rationing system and the searching tools fully met their expectations until late April when the government was able to produce ample numbers of masks domestically. ${ }^{31}$

Movement tracking applications keep track of the people whom an individual comes into contact with on a daily basis and could prove useful in contact tracing when one gets infected with COVID-19. Although our findings showed that the majority $(66.1 \%$ in EA and $80.3 \%$ in SEA) were willing to download a contact tracing application, the reality might be different. In Singapore, a movement tracking mobile phone application called 'TraceTogether' was initially only used by one-fifth of the Singaporean population, rendering its implementation ineffective. ${ }^{32}$ However, the adoption of the TraceTogether app and tokens stand at more than $60 \%$ by December 2020 after widespread distribution of the tokens to its residents and reassurance that their data are stored in the device and will not be shared unless there is an infection. Adoption could also have increased because the app or token is now required to enter more places, such as cinemas. There is a need for future research to identify other successful interventions to encourage more people to use tracing application, and data privacy being one potential barrier. ${ }^{33}$

In our study, men were found to be less compliant with physical distancing measures. This was also consistent with the Chinese H1N1 KAP study, ${ }^{11}$ which found that men were more likely to go to crowded places and not wear masks outside their homes. Based on previous studies, ${ }^{34-36}$ men were also found to be more likely to engage in risk-taking behaviours. 


\section{Public health recommendations}

As psychological well-being is associated with high compliance in our study, to possibly increase the impact of public health policy and intervention, psychological well-being should be addressed in risk communication and assessment of the pandemic. Pandemic preparedness planning should also include components to increase psychological well-being towards public health measures such as vaccine uptake. In a Chinese study, good COVID-19 knowledge was associated with optimistic attitudes and appropriate practices towards COVID-19. ${ }^{30}$ This is important in people who come from the lower-income group or have lower educational level as they tend to be less motivated to know about the disease and prevention measures, and they may not have access to accurate information, high quality of medical care and housing. For example, Singapore's migrant worker outbreak, due to lack of physical distancing in poorly ventilated dormitories, highlights the vulnerability and burden of this highly susceptible subpopulation during this crisis. ${ }^{37}$ Additionally, it was reported that there was a spate of suicides and attempted suicides involving migrant workers living at the dormitories due to uncertainties over their health, jobs and prolonged confinement. ${ }^{38}$ Hence, risk communication plays an important role in compliance with precautionary measures as well as reducing anxiety about the pandemic. Mental health outreach also needs to be expanded to meet the increasing demands.

In our study, we inferred that a high level of discipline would possibly be needed for the sustainability of physical distancing measures. Questions in our questionnaire such as unwillingness to continue with physical distancing and going out houses frequently were significantly associated with poor compliance. Interestingly, in a Chinese study, high level of self-control buffers the association between perceived severity of COVID-19 as a risk factor for mental health problems. ${ }^{39}$ The COVID-19 pandemic illustrates uncertainty, shifting circumstances and rapidly changing recommendations. Restrictions on activities often have major economic implications and impingement on civil liberties. ${ }^{40}$ Singapore has one of the most restrictive physical distancing policies in the world. The quick adoption of such restrictive policies has been possible due to public trust and confidence in the government's capacity for crisis management such as Multi-Ministry Taskforce in coordinating pandemic efforts and active communication through local news media in a timely manner. ${ }^{41}$ Given these collective efforts, the mortality rate in Singapore remains low compared with that of many other nations (as of 3 May 2020, according to the statistics by WHO (2020), the global mortality rate is $6.99 \%$, compared with $0.0989 \%$ in Singapore). Hence, building public confidence is paramount so that the public is motivated to have self-discipline to follow government's recommendations, which also reduces anxiety in overall mental health.

To encourage a high level of discipline, public health messaging could focus on males and younger age group. Our study also showed that older age was significantly associated with high compliance behaviour and male gender was found to be less compliant with physical distancing measures. Male is identified as a risk factor for death and intensive care unit admission, ${ }^{42}$ which could be associated with gender-based sociocultural and behavioural differences. By tackling gender as an element of social systems and structures through addressing the association of males with risk-taking behaviours in COVID-19 pandemic, health promotion will enhance health and social outcomes. ${ }^{43}$ Adolescents and young adults were identified internationally as a group with potentially low compliance rates with public health measures. ${ }^{44}$ Growing evidence shows that young people are more likely to get infected with the new variant in Brazil $^{45}$ and new outbreaks in Singapore were found in tuition centres and schools. ${ }^{46}$ Hence, public campaigns can be targeted at young people to increase their compliance as they are not spared from COVID-19, compared with the older age.

Public health intervention that focuses on social responsibility for behavioural change is also crucial. Questions such as standing more than $1 \mathrm{~m}$ apart and wearing a mask when they had influenza-like symptoms before the COVID-19 pandemic were significantly associated with high compliance. Solidarity and social responsibility of the public have been a key to Vietnam's success in combating COVID-19 to date, with only just over 300 cases by 20 May 2020 and not a single death. Given Vietnam's weak healthcare system and low budget, the government's call for precautionary measures using messages such as 'to stay home is to love your country' must have necessitated a rapid collective response. ${ }^{47}$ The recent new outbreak of COVID-19 cases in EA such as Japan and South Korea in April $2021^{48}$ could be associated with complacency with preventive measures. In our study, subjects from EA were less likely to stay at home when they were unwell and to participate in contact tracing applications during our survey period in May 2020 after their peak of COVID19. Vigilance on resurgence of COVID-19 cases through continued and collective efforts on compliance with physical distancing and personal hygiene after recovery and vaccinations have to be emphasised to the public by our governments. Thus, policies to relish public's togetherness to encourage social responsibility is critical to prevent and delay occurrence of new waves of COVID-19 transmission. Community empowerment should be a key component in building pandemic preparedness.

\section{Limitations of the study}

Our study cohort may not be truly representative of the demographics of the various countries as participants were recruited via networks of healthcare workers and disseminated through different social media platforms. The relatively high rate of respondents working in healthcare sector and having tertiary education indicate a potential selection bias inadvertently introduced into the study, which may overestimate the level of KAP in our study group. The second limitation is the KAP instrument used in this study. 
A more thorough assessment of instrument validity and reliability would have produced a more robust instrument. Possible factors contributing to KAP, such as health literacy, were not measured in this study, which may overestimate the risk effect observed. Moreover, there can be a potential recall and social desirability bias, as participants may have answered the attitude and practice questions positively based on what they perceive to be expected of them.

This cross-sectional study design can only demonstrate associations between patterns and social-demographic variables and causation cannot be attributed to the findings. A further cohort-based study design should be considered to monitor and assess changes in KAP patterns to evaluate the effectiveness of the different policies and intervention implemented to guide subsequent policies as part of the overall risk management framework.

\section{CONCLUSION}

Older individuals, female, healthcare workers, individuals with preference of online news and social media, social responsibility, discipline and high psychological well-being are factors associated with high compliance behaviour towards personal hygiene and physical distancing measures in the early phase of pandemic. In the next step of public policy formulation, public health communication and community empowerment could be improved by focusing at these factors to target the entire population in all its diversity, regardless of languages, cultures, education and socioeconomic level.

\section{Author affiliations}

${ }^{1}$ Department of Medicine, Yong Loo Lin School of Medicine, National University Hospital, Singapore

${ }^{2}$ Division of Gastroenterology \& Hepatology, Department of Medicine, National University Hospital, Singapore

${ }^{3}$ Department of Clinical Psychology, James Cook University, Singapore

${ }^{4}$ Department of Medicine, Yong Loo Lin School of Medicine, National University of

Singapore, Singapore

${ }^{5}$ Department of Paediatrics, Yong Loo Lin School of Medicine, National University of Singapore, Singapore

${ }^{6}$ Saw Swee Hock School of Public Health, National University of Singapore and National University Health System, Singapore

${ }^{7}$ Department of Medicine, $\mathrm{Ng}$ Teng Fong General Hospital, Singapore

${ }^{8}$ Singapore Institute for Clinical Sciences (SICS), Agency for Science Technology and Research, Singapore

${ }^{9}$ Department of Otorhinolarygology, Head and Neck Surgery, Universiti Putra Malaysia, Serdang, Selangor, Malaysia

${ }^{10}$ Department of Anaesthesiology, Columbia Asia Hospitals Pvt Ltd, Sarawak, Malaysia

${ }^{11}$ Cambridge Paediatrics, Hong Kong

${ }^{12}$ Department of Gastroenterology, Sheikh Russel National Gastroliver Institute and Hospital, Dhaka, Bangladesh

${ }^{13}$ Department of Gastroenterology, Sanjay Gandhi Postgraduate Institute Medical

Science, Lucknow, India

${ }^{14}$ Medicine and Therapeutics, The Chinese University of Hong Kong Faculty of

Medicine, Hong Kong

${ }^{15}$ State Key Laboratory of Pharmaceutical Biotechnology, University of Hong Kong, Hong Kong

${ }^{16}$ Division of Gastroenterology, Department of Internal Medicine, University of Indonesia, Depok, Jawa Barat, Indonesia

${ }^{17}$ Departments of Gastroenterology and Hepatology, the First Affiliated Hospital, Sun Yat-sen University First Affiliated Hospital, Guangzhou, Guangdong, China
${ }^{18}$ Department of Gastroenterology, Wuhan Union Hospital of Huazhong University of Science and Technology, Wuhan, China

${ }^{19}$ China Academy of Chinese Medical Sciences, Xiyuan Hospital, Beijing, China

${ }^{20}$ Department of Medicine, Buddhist Tzu Chi Hospital and University School of Medicine, Hualien, Taiwan

${ }^{21}$ Gut Research Group, Faculty of Medicine, Universiti Kebangsaan Malaysia, Bangi, Selangor, Malaysia

${ }^{22}$ Department of Medicine, The Medical City, Pasig City, Manila, Philippines

${ }^{23}$ Wonkwang Digestive Disease Research Institute, Gut and Food Healthcare, Wonkwang University School of Medicine Hospital, Iksan, Jeollabuk-do, Korea (the Republic of)

${ }^{24}$ Division of Gastroenterology and Hepatology, Hyogo College of Medicine, Nishinomiya, Hyogo, Japan

Correction notice This article has been corrected since it was published. Middle initial has been added for Uday C Ghoshal.

Twitter Yeong Yeh Lee @justntweet

Contributors JP, KTHS: Conception and design of the research. CEC, GSK, SQ, EXLL, AD, SW, HXL, HG, JP: Acquisition, analysis and interpretation of research data. CEC, GSK, JP, EXSL, TLL, SLO, ECWH, MMR, UG, HW, CKYC, AFS, NT, YX, J-SL, FL, C-LC, YYL, RMM: Conduct of the research, drafting and revising the final document critically for important intellectual content. Y-SK, TO, HM: Critical review of the final document. JP, KTHS, CEC, GSK: Revision and final approval of the final document and served as guarantors for the study.

Funding This project was funded by the National University of Singapore (NUS) IPUR research grant (IPUR_FY2020_RES_02_PANG) and NUS COVID-19 Seed Research Grant (NUSCOVID19RG-43).

Map disclaimer The inclusion of any map (including the depiction of any boundaries therein), or of any geographic or locational reference, does not imply the expression of any opinion whatsoever on the part of BMJ concerning the legal status of any country, territory, jurisdiction or area or of its authorities. Any such expression remains solely that of the relevant source and is not endorsed by BMJ. Maps are provided without any warranty of any kind, either express or implied.

Competing interests None declared.

Patient consent for publication Not required.

Ethics approval Ethics approval was obtained for this study.

Provenance and peer review Not commissioned; externally peer reviewed.

Data availability statement All data relevant to the study are included in the article or uploaded as supplemental information.

Supplemental material This content has been supplied by the author(s). It has not been vetted by BMJ Publishing Group Limited (BMJ) and may not have been peer-reviewed. Any opinions or recommendations discussed are solely those of the author(s) and are not endorsed by BMJ. BMJ disclaims all liability and responsibility arising from any reliance placed on the content. Where the content includes any translated material, BMJ does not warrant the accuracy and reliability of the translations (including but not limited to local regulations, clinical guidelines, terminology, drug names and drug dosages), and is not responsible for any error and/or omissions arising from translation and adaptation or otherwise.

Open access This is an open access article distributed in accordance with the Creative Commons Attribution Non Commercial (CC BY-NC 4.0) license, which permits others to distribute, remix, adapt, build upon this work non-commercially, and license their derivative works on different terms, provided the original work is properly cited, appropriate credit is given, any changes made indicated, and the use is non-commercial. See: http://creativecommons.org/licenses/by-nc/4.0/.

ORCID iDs

Chun En Chua http://orcid.org/0000-0002-0338-5589

Uday C Ghoshal http://orcid.org/0000-0003-0221-8495

Yeong Yeh Lee http://orcid.org/0000-0002-6486-7717

Junxiong Pang http://orcid.org/0000-0002-9788-701X

\section{REFERENCES}

1 WHO. WHO coronavirus disease (COVID-19) Dashboard, 2021. Available: https://covid19.who.int/ [Accessed 25 May 2021]. 
2 Baden LR, El Sahly HM, Essink B, et al. Efficacy and safety of the mRNA-1273 SARS-CoV-2 vaccine. N Engl J Med Overseas Ed 2021;384:403-16.

3 Moghadas SM, Vilches TN, Zhang K, et al. The impact of vaccination on COVID-19 outbreaks in the United States. Clin Infect Dis 2021:ciab079.

4 Lazarus JV, Ratzan S, Palayew A, et al. COVID-SCORE: a global survey to assess public perceptions of government responses to COVID-19 (COVID-SCORE-10). PLoS One 2020;15:e0240011.

5 World Health Organization. Advice for the public on COVID-19. Available: https://www.who.int/emergencies/diseases/novelcoronavirus-2019/advice-for-public

6 Barkur G, Vibha K, Kamath GB. Sentiment analysis of nationwide lockdown due to COVID 19 outbreak: evidence from India. Asian J Psychiatr 2020:51:102089.

7 Kanniah KD, Kamarul Zaman NAF, Kaskaoutis DG, et al. COVID-19's impact on the atmospheric environment in the Southeast Asia region. Sci Total Environ 2020;736:139658.

8 Mohan M. COVID-19 circuit breaker extended until Jun 1 as Singapore aims to bring down community cases 'decisively': PM Lee, 2020. Available: https://www.channelnewsasia.com/news/ singapore/covid-19-circuit-breaker-extended-june-pm-lee-speechapr-21-12662054

9 EOH S. Malaysia extends MCO to Feb 18, tougher restrictions in store, 2021The Straits Times. Available: <https://www.straitstimes. com/asia/se-asia/malaysia-to-extend-movement-curbs-by-twoweeks-to-feb-18-as-infection-rates-remain-high> [Accessed 28 Feb 2021].

10 Gov.sg. COVID-19 (coronavirus disease 2019), 2021. Available: <https://www.gov.sg/features/covid-19> [Accessed 28 Feb 2021].

11 Lin Y, Huang L, Nie S, et al. Knowledge, attitudes and practices (KAP) related to the pandemic (H1N1) 2009 among Chinese general population: a telephone survey. BMC Infect Dis 2011;11:128.

$12 \mathrm{Gao} \mathrm{H}, \mathrm{Hu}$ R, Yin L, et al. Knowledge, attitudes and practices of the Chinese public with respect to coronavirus disease (COVID-19): an online cross-sectional survey. BMC Public Health 2020;20:1816.

13 Azlan AA, Hamzah MR, Sern TJ, et al. Public knowledge, attitudes and practices towards COVID-19: A cross-sectional study in Malaysia. PLoS One 2020;15:e0233668.

14 Chan EYY, Huang Z, Lo ESK, et al. Sociodemographic predictors of health risk perception, attitude and behavior practices associated with Health-Emergency disaster risk management for biological hazards: the case of COVID-19 pandemic in Hong Kong, SAR China. Int J Environ Res Public Health 2020;17:3869.

15 pp.Han E, Tan MMJ, Turk E, et al. Lessons learnt from easing COVID-19 restrictions: an analysis of countries and regions in Asia Pacific and Europe. The Lancet 2020;396:1525-34.

16 Keyes CLM. Mental illness and/or mental health? investigating axioms of the complete state model of health. J Consult Clin Psychol 2005;73:539-48.

17 Keyes CLM. The mental health continuum: from languishing to flourishing in life. J Health Soc Behav 2002;43:207-22.

18 Petrillo G, Capone V, Caso D, et al. The mental health ContinuumShort form (MHC-SF) as a measure of well-being in the Italian context. Soc Indic Res 2015;121:291-312.

19 Lim Y-J. Psychometric characteristics of the Korean mental health Continuum-Short form in an adolescent sample. J Psychoeduc Assess 2014;32:356-64

20 Keyes CLM, Wissing M, Potgieter JP, et al. Evaluation of the mental health continuum-short form (MHC-SF) in setswana-speaking South Africans. Clin Psychol Psychother 2008;15:181-92.

21 Gilbert M, Dewatripont M, Muraille E, et al. Preparing for a responsible lockdown exit strategy. Nat Med 2020;26:643-4.

22 Dong L, Bouey J. Public mental health crisis during COVID-19 pandemic, China. Emerg Infect Dis 2020;26:1616-8.

23 Miller LJ, Lu W. U.S. near bottom, Hong Kong and Singapore at top of health Havens, 2018Bloomberg. Available: https://www. bloomberg.com/news/articles/2018-09-19/u-s-near-bottom-ofhealth-index-hong-kong-and-singapore-at-top

24 Peltzer K, Pengpid S, Sodi T, et al. Happiness and health behaviours among university students from 24 low, middle and high income countries. Journal of Psychology in Africa 2017;27:61-8.
25 So ES, Park BM. Health behaviors and academic performance among Korean adolescents. Asian Nurs Res 2016;10:123-7.

26 Diener E, Pressman SD, Hunter J, et al. If, why, and when subjective well-being influences health, and future needed research. Appl Psychol Health Well Being 2017;9:133-67.

27 Lyubomirsky S, King L, Diener E. The benefits of frequent positive affect: does happiness lead to success? Psychol Bull 2005;131:803-55.

28 Kye SY, Park K. Health-Related determinants of happiness in Korean adults. Int J Public Health 2014;59:731-8.

29 Boehm JK, Soo J, Zevon ES, et al. Longitudinal associations between psychological well-being and the consumption of fruits and vegetables. Health Psychol 2018;37:959-67.

30 Zhong B-L, Luo W, Li H-M, et al. Knowledge, attitudes, and practices towards COVID-19 among Chinese residents during the rapid rise period of the COVID-19 outbreak: a quick online cross-sectional survey. Int J Biol Sci 2020;16:1745-52.

31 knowledge@Wharton. Taiwan's tech-savvy citizens helped flatten its COVID-19 curve. Available: https://knowledge.wharton.upenn.edu/ article/taiwans-tech-savvy-citizens-helped-flatten-covid-19-curve/

32 Woo JJ. Policy capacity and Singapore's response to the COVID-19 pandemic. Policy and Society 2020;39:345-62.

33 CNA. TraceTogether adoption up to more than $60 \%$ as privacy concerns wane; users still bothered about battery drain, 2021. Available: <https://www.channelnewsasia.com/news/singapore/ tracetogether-app-token-adoption-phase-3-13748714> [Accessed 28 Feb 2021]

34 Pawlowski B, Atwal R, Dunbar RIM. Sex differences in everyday risktaking behavior in humans. Evolutionary Psychology 2008;6:29-42.

35 Cobey KD, Stulp G, Laan F, et al. Sex differences in risk taking behavior among Dutch cyclists. Evol Psychol 2013;11:350-64.

36 Duell N, Steinberg L, lcenogle G, et al. Age patterns in risk taking across the world. J Youth Adolesc 2018;47:1052-72.

37 Leung $\mathrm{H}$. Virus Outbreak Among Singapore's Migrants Serves as Warning, 2020. Available: https://time.com/5825261/singaporecoronavirus-migrant-workers-inequality/

38 Phua R. COVID 19: no spike in number of migrant worker suicides, says MOM, 2020. Available: https://www.channelnewsasia.com/ news/singapore/migrant-workers-mental-health-suicides-covid-19mom-12989854

39 Li J-B, Yang A, Dou K, Cheung RYM, et al. Self-Control moderates the association between perceived severity of coronavirus disease 2019 (COVID-19) and mental health problems among the Chinese public. Int J Environ Res Public Health 2020;17:4820.

40 Isaacs D, Britton PN, Preisz A. Ethical reflections on the COVID-19 pandemic: the epidemiology of panic. J Paediatr Child Health 2020;56:690-1.

41 Abdullah WJ, Kim S. Singapore's Responses to the COVID-19 Outbreak: A Critical Assessment. The American Review of Public Administration 2020;50:770-6.

42 Peckham H, de Gruijter NM, Raine C, et al. Male sex identified by global COVID-19 meta-analysis as a risk factor for death and ITU admission. Nat Commun 2020;11:6317.

43 Pederson A, Greaves L, Poole N. Gender-transformative health promotion for women: a framework for action. Health Promot Int 2015;30:140-50.

44 Nivette A, Ribeaud D, Murray A, et al. Non-Compliance with COVID-19-related public health measures among young adults in Switzerland: insights from a longitudinal cohort study. Soc Sci Med 2021;268:113370.

45 Taylor L. Covid-19: Brazil's spiralling crisis is increasingly affecting young people. BMJ 2021;373:n879.

46 CNA. 34 new community COVID-19 cases in Singapore, including 5 students and 2 pre-school teachers, 2021. Available: https://www. channelnewsasia.com/news/singapore/covid-19-community-casesmay-19-clusters-pre-school-teachers-14838394

47 Ivic S. Vietnam's Response to the COVID-19 Outbreak. Asian Bioeth Rev 2020;12:341-7.

48 CHOON C. Covid-19 surge in Asia: fourth wave looms in South Korea, 2021The Straits Times. Available: https://www.straitstimes. com/asia/east-asia/covid-19-surge-in-asia-fourth-wave-looms-insouth-korea 